
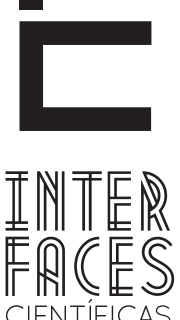

HUMANASE SOCIAIS

ISSN IMPRESSO 2316-3348

E-ISSN 2316-3801

DOI - 10.17564/2316-3801.2016v5n2p53-66

\title{
A PRÁTICA REFLEXIVA DE UM CONSELHO PROFISSIONAL A PARTIR DAS SUAS PRÁTICAS E PRATICANTES
}

THE REFLECTIVE PRACTICE OF A PROFESSIONAL ASSOCIATION BASED ON THEIR PRACTICES AND PRACTITIONERS

LA PRÁCTICA REFLEXIVA DE UN COLEGIO PROFESIONAL BASADO EN SUS PRÁCTICAS Y PRACTICANTES

\section{RESUMO}

O desenvolvimento dos estudos sobre estratégia levou a um direcionamento das pesquisas para o nível do estrategista, como uma forma de conhecer a estratégia empresarial a partir daqueles que efetivamente a executam. Nessa perspectiva, a Estratégia como Prática Social enfatiza a importância de um conjunto de atividades que emerge de interações sociais, formando a estratégia. Tais atividades podem ser analisadas a partir da prática reflexiva, uma ação espontânea e habitual que ocorre durante as práticas cotidianas. Esta pesquisa possui, como objetivo principal, analisar a prática reflexiva de um conselho profissional, o Conselho Regional de Administração de Sergipe (CRA/ $\mathrm{SE}$ ), a partir de suas práticas e praticantes. A pesqui- sa possui natureza qualitativa e classifica-se como descritiva, sendo um estudo de caso único. Os dados foram coletados por meio de entrevistas com representantes da organização, sendo efetuada uma análise de conteúdo. Os resultados apontam que há pouco espaço para a reflexividade por questões de estrutura organizacional e da dinâmica do trabalho.

\section{PALAVRAS-CHAVE}

Estratégia. Prática Reflexiva. Práticas. Praticantes. Conselho Profissional. 


\section{ABSTRACT}

The evolution of the studies on strategy led to an orientation of research to the level of the strategist, as a way to know the business strategy from those who really do it. In this view, the Strategy-as-Practice emphasizes the importance of a set of activities emerging from social interactions, building the strategy. Such activities can be analyzed using the reflective practice, a spontaneous and habitual action that occurs during daily practices. This research aims to analyze the reflective practice of a professional association (State of Sergipe's Regional Council of Management), from its practices and practitioners. It is a qualitative and descriptive research, and it is also a single case study. Data were collected by interviews with representatives of the organization, and a content analysis was done. The results show that there is a short space for reflection due to issues related to the organizational structure and work dynamics.

\section{KEYWORDS}

Strategy. Reflective Practice. Practices. Practitioners. Professional Association.

\section{RESUMEN}

La evolución de los estudios sobre la estrategia condujo a una orientación de la investigación al nivel del estratega, como una forma de conocer la estrategia de negocios de los que realmente hacen. En esta visión, la Estrategia-como-Práctica hace hincapié en la importancia de un conjunto de actividades que surgen de las interacciones sociales, construyendo la estrategia. Tales actividades pueden ser analizadas mediante la práctica reflexiva, una acción espontánea y habitual que se produce durante las prácticas diarias. Esta investigación tiene como objetivo analizar la práctica reflexiva de un colegio profesional, el Conselho Regional de Administração de Sergipe (CRA/SE), a partir de sus prácticas y profesionales.
Se trata de una investigación cualitativa y descriptiva, siendo un estudio de un solo caso. Los datos fueron recogidos mediante entrevistas con representantes de la organización y se realizó un análisis de contenido. Los resultados muestran que hay un corto espacio para reflexión debido a problemas relacionados con la estructura y dinámica de la organización de trabajo.

\section{PALABRAS-CLAVE}

Estrategia. Práctica Reflexiva. Práctica. Practicantes. Colegio Profesional. 


\section{INTRODUÇ̄̃̃O}

A estratégia tem sido vista pela maioria dos pesquisadores do campo como uma propriedade das organizações, por fatores como estratégias de diversificação, processos de decisão e mudança, dentre outros. Diferentemente dessa visão, uma perspectiva aponta a estratégia como uma atividade. Segundo Johnson e outros autores (2007), o processo estratégico envolve pessoas, fazendo estratégias, e cada organização agirá de forma diferente perante um dado processo. No entanto, o "fazer estratégico" é visto de forma superficial, não atingindo o âmago da questão - a pesquisa deve buscar o quê, literalmente e diretamente, as pessoas fazem.

A partir do estudo de Whittington (1996), a Estratégia como Prática Social (Strategy-as-Practice) considera a figura do estrategista, entendendo-o como um praticante de qualquer nível hierárquico cujas ações e interações dentro da organização estão relacionadas ao "fazer estratégico". É uma abordagem que, na construção da estratégia, considera as microatividades; assim, uma forma adequada de compreendê-las é a partir da prática reflexiva, descrita por Schön (2000) como uma ação espontânea e habitual que ocorre nas práticas cotidianas.

Dessa forma, a presente pesquisa possui como objetivo a análise da prática reflexiva de um conselho profissional, a partir de suas práticas e praticantes. 0 órgão pesquisado foi o Conselho Regional de Administração de Sergipe (CRA/SE), uma organização em que indivíduos fazem e refazem um sistema compartilhado de práticas estratégicas, a partir de um processo cultural e legal, decorrente da atuação da organização como órgão consultivo, orientador, disciplinador e fiscalizador do exercício da profissão de administrador.

\section{ESTRATÉGIA COMO PRÁTICA SOCIAL}

Tradicionalmente, estratégia é alvo de definições distintas por parte dos pesquisadores, como apontam Mintzberg e outros autores (2007). Um entendimento da estratégia abrange várias definições de estratégias como plano/pretexto, padrão, posição e perspectiva. As duas primeiras definições são usadas para nos levar da noção de estratégia deliberada - além da visão tradicional do termo - até a noção de estratégia emergente. Assim, as estratégias podem fazer parte de uma organização sem que tenham sido anteriormente formuladas.

No entanto, Jarzabkowski e Spee (2009) criticam a teoria tradicional sobre estratégia, ao dizer que em seu posterior desenvolvimento, os estudos passaram a ser povoados por análises multivariadas sobre o desempenho da firma, havendo uma ausência dos atores humanos e suas ações, reduzindo-os em dados estatísticos. Dessa forma, a pesquisa sobre estratégia carecia de humanização.

Como elucidam Jarzabkowski e Spee (2009), a Estratégia como Prática Social coloca os atores e as suas ações e interações (quem a realiza, o que eles fazem, como fazem, que ferramentas utilizam e as implicações de suas ações) no centro da análise da estratégia. Assim, devem ser concebidos os relacionamentos como fator central nas análises, superando a dicotomia micro/macro existente no campo da estratégia.

Isso fica claro na afirmação de Jarzabkowski (2004) de que a estratégia deve ser examinada não como algo que a empresa tem, mas como algo que a empresa faz - é um saber que existe a partir das ações e decisões tomadas. A ação deve ser considerada numa perspectiva micro, e não ser definida em função de resultados, o que limita o potencial de análise dos 
estudos. A Estratégia como Prática Social voltou-se para o nível micro, com foco nas práticas.

Em seu artigo seminal sobre a Estratégia como Prática Social, Whittington (1996) apontou que a pesquisa sobre os estrategistas, na perspectiva da estratégia como prática, considera certos empregados de fora da alta gerência como atores estratégicos importantes, de forma a discernir interpretações, discursos e motivações usados na elaboração da estratégia. Essa perspectiva tem implicações em relação à perspectiva dominante, no conhecimento do profissional, na forma de ensino da estratégia e no foco da pesquisa acadêmica, resumidos na Figura 1:

Figura 1 - Implicações da Estratégia como Prática Social
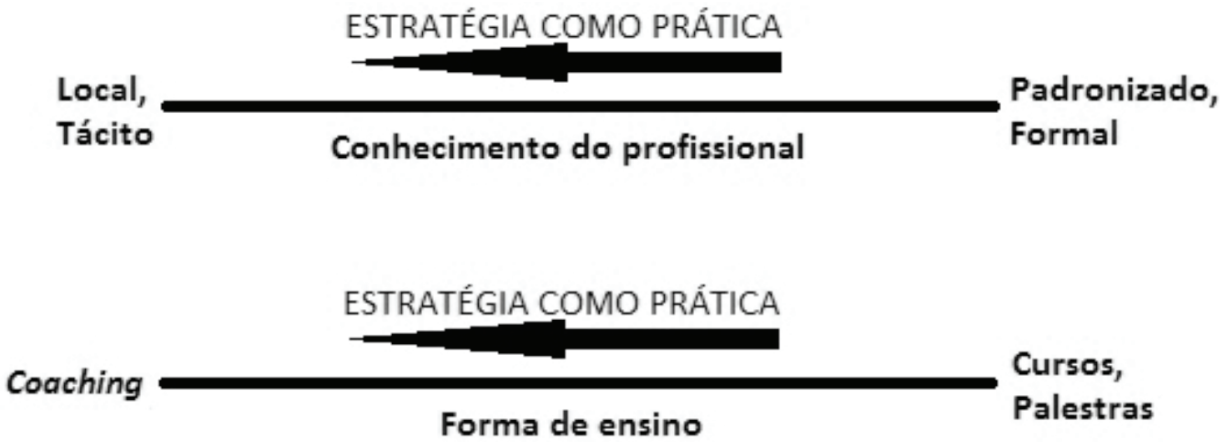

\section{ESTRATÉGIA COMO PRÁTICA

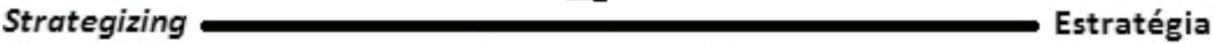 \\ Foco da pesquisa}

Fonte: Whittington (1996).

Em relação à atuação profissional, o aprendizado obtido com a experiência na organização possui importância semelhante ao aprendizado formal. A Estratégia como Prática Social indica que os papéis diferentes adotados pelos estrategistas dentro da organização implicam na formulação de diferentes estratégias, e que os superiores hierárquicos devem assegurar o aprendizado e as experiências mais adequadas para o desenvolvimento dos subordinados. Já em relação à forma de ensino, o educador deve ser um conhecedor da estratégia específica do campo de atuação da organização. O seu papel deve ir além de um simples conferencista, mas deve ser o de um conselheiro ou de um treinador (coach), e o ensino deve buscar a exploração mútua dos problemas, reflexão e prática constante do que é aprendido.

Em relação ao foco da pesquisa, se o aprendizado ao longo do tempo se deu sobre várias estratégias, na perspectiva da Estratégia como Prática Social busca-se aprender sobre o "estrategizar" (strategizing), conceituado por Johnson e outros autores (2007) como o que as pessoas realizam no processo de elaboração e execução da estratégia, ou as ações tomadas nesse processo. Segundo Whittington (1996), os interesses da pesquisa devem residir nas habilidades adquiridas pelos estrategistas, enfatizando o desempenho individual, em vez do desempenho da empresa. 
Conforme apontam Jarzabkowski, Balogun e Seidl (2007), esse processo de "fazer estratégia" ocorre a partir da convergência de três aspectos: a práxis ou prática (rotinas dos atores organizacionais e a relação entre essas ações e o contexto institucional, social e organizacional em que elas ocorrem), as práticas (tradições, rotinas, procedimentos e normas que constituem o trabalho da estratégia, por meio dos hábitos sociais caracterizados na forma de fazer determinada atividade cultural) e os praticantes (atores da ação, indivíduos que fazem e refazem um sistema de práticas estratégicas compartilhadas).

Há grandes desafios para o futuro da pesquisa nesse campo. Para Jarzabkowski e Spee (2009), os diversos trabalhos empíricos nesse campo originados da última década sinalizam não haver mais espaço para pesquisas empíricas. A questão passa a analisar a prática baseada em conjuntos de dados, em pesquisas longitudinais, com foco qualitativo. No entanto, 0 desafio para o campo de Estratégia como Prática Social na próxima década é buscar uma complementaridade, quando possível, com outros campos de estudo de forma a iluminar os fenômenos do campo e gerar novas perguntas.

\section{PRÁTICA REFLEXIVA}

Uma forma de se compreender as microatividades é a partir da prática reflexiva, descrita por Schön (2000) como uma ação espontânea e habitual que acontece nas práticas cotidianas, quando os praticantes aprendem a realizar certa atividade e a executam de uma forma "automática", devido à internalização das ações de reconhecimento, decisões e ajustes. A prática reflexiva considera que a construção do conhecimento profissional se fundamenta em fatores ambíguos e indeterminados, longe de uma racionalidade técnica. A reflexão contínua no contexto organizacional é vista como o caminho para a evolução e melhoria.
É necessário, antes de desenvolver a questão da prática reflexiva, entender o que é a reflexão. Clarà (2014) apresenta uma noção descritiva da reflexão, como um pensamento espontâneo que busca dar coerência a uma dada situação. É uma contínua interação entre inferência e observação que leve a uma conclusão, podendo ou não ter implicações diretas na ação a ser tomada. São apresentados três conceitos sobre a reflexão ainda sem validação empírica, necessitando de pesquisas a respeito: a reflexão como um processo de tomada de decisão, como uma articulação entre teoria e prática e como uma sequência consecutiva de etapas.

A concepção da prática reflexiva, segundo Schön (2000, p. 72) fundamenta-se em três ideias: "conhecimento na ação", "reflexão na ação" e "reflexão sobre a reflexão na ação". 0 primeiro se refere às ações, reações e julgamentos espontâneos, em que muitas vezes não há ideia de como se aprende a fazer essas coisas, simplesmente as pessoas fazem-nas. Para o profissional, esse é um tipo de conhecimento intuitivo e experimental, implícito em suas ações cotidianas.

Já a "reflexão na ação" é o exercício contínuo de pensar sobre aquilo que se faz, quando o profissional se pergunta sobre os critérios utilizados para efetuar determinada ação ou decisão, para lidar com incertezas e conflitos. Por fim, a "reflexão sobre a reflexão na ação" é o ato de refletir sobre o que foi refletido, de forma que o profissional construa uma maneira própria de pensar, entender e agir diante dos fatos, para prever problemas que podem surgir e possíveis soluções. Essa última postura leva ao aprendizado da profissão baseado na experiência.

0 profissional reflexivo, na perspectiva de Roglio (2009), é um profissional fundamentado na inter-relação entre os pensamentos crítico (o ato de pensar e repensar a situação, o ambiente e os envolvidos, fatores políticos, históricos e sociais e as interações de cada um deles), criativo (a observação das situações de forma sistêmica, com vistas a buscar soluções alternativas para possíveis problemas) e introspectivo 
(a compreensão sobre os valores, experiências, atitudes, emoções e intuições em relação à situação), de forma que o profissional reflexivo seja um arquiteto e facilitador de novas abordagens. Também se considera que a prática reflexiva é influenciada pelo repertório do praticante, pois as experiências passadas, as imagens, as percepções e ações são usadas como referências para a compreensão de eventos inesperados, ajudando a lidar com eles.

A importância da prática reflexiva para o profissional está, segundo Reis, Silva e Eboli (2010), na ideia difundida e equivocada de que diariamente os profissionais lidam com problemas claros e relações lineares de causa e efeito, com a aplicação de técnicas bem definidas. Porém, nos contextos organizacionais atuais, estão presentes fatores como incertezas, problemas pouco delineados, mudanças constantes e relações de causa e efeito complexas.Segundo Roglio (2009), a ação e a reflexão na prática administrativa são essenciais, pois os praticantes devem parar, pensar e refletir sobre experiências passadas, sendo importante analisar o passado antes de usar o presente a fim de obter um futuro melhor.

Para Silva e Silva (2011), o acúmulo de situações já vivenciadas pelo profissional influencia diretamente na forma como os gerentes aprendem, pois a aprendizagem por meio da experiência, na prática do local de trabalho, transforma o ambiente ao redor em sala de aula, por meio das experiências do cotidiano, das situações práticas decorrentes da natureza do trabalho, da aprendizagem informal como fonte relevante de aprendizagem pela experiência e do aumento da importância atribuída pelos gerentes à reflexão, que ocorre durante ou após a ação.

0 aprendizado por meio da experiência envolve a reflexão, pois como apontam Silva e Silva (2011), trata-se de rever os eventos passados, o que traz sentido às ações e eventualmente, encontrando novas formas de atuar em eventos futuros. Esse processo de aprendizagem tem total relação com a Estratégia como Prá- tica Social, pois é enxergado como uma atividade cotidiana, em que os estilos individuais de aprendizagem influenciam os processos decisórios.

Segundo Reis, Silva e Eboli (2010), a prática reflexiva é um mecanismo de aprendizado que possibilita ao indivíduo realizar conexões entre a teoria e a prática organizacional durante a execução do trabalho numa constante aplicação e reaplicação de conhecimentos, com as vantagens de ser acessível, flexível, dinâmico e eficaz.

A reflexão é necessária para a prática profissional, pois segundo Souza-Silva e Davel (2007), o processo reflexivo se inicia a partir do momento que o indivíduo toma um dado evento do passado como metáfora, de forma a ver as semelhanças e diferenças entre fenômenos, contribuindo ao gerar um senso de continuidade entre as práticas ao longo do tempo. Assim, o aprendizado ocorre a partir desse exercício metafórico-reflexivo de comparar práticas passadas com atuais, de perceber as variações presentes nas novas práticas e conceber resoluções para os problemas apresentados, de forma contínua. As experiências de reflexões enriquecem o repertório de percepções, explanações, invenções e soluções do profissional para que, no futuro, ele lide melhor com novas práticas e seus problemas e resoluções.

\section{METODOLOGIA}

Com base na terminologia utilizada por Saunders, Lewis e Thornhill (2007), o presente estudo é de natureza qualitativa. Já a estratégia de pesquisa utilizada é o estudo de caso, que envolve uma investigação empírica de um fenômeno atual, inserido no contexto de vida real, usando fontes múltiplas de evidência, de forma a compreender o contexto de determinada situação.

Em relação ao uso de um único caso na pesquisa, algo rejeitado ou relegado a um papel secundário por muitos pesquisadores, Mariotto, Zanni e Moraes 
(2014) defendem que ele é capaz de ser utilizado como uma fonte de conhecimento em diversas áreas; seja como um exemplo a ser seguido, uma amostra do que pode acontecer, ou como fonte de experiência indireta, e que muitas das críticas feitas ao método do estudo de caso (falta de rigor científico e incapacidade de proporcionar uma base para a generalização dos resultados) decorrem de uma abordagem positivista para a construção do conhecimento.Os autores defendem não ser essa a única forma de geração e difusão de conhecimento, mas que é preciso uma meIhor compreensão das diferentes convicções filosóficas existentes para seu uso adequado em cada pesquisa ou sua etapa, a partir de um diálogo reflexivo.

A organização analisada na presente pesquisa é o Conselho Regional de Administração de Sergipe. Um conselho profissional é uma forma sui generis de organização, que fiscaliza o exercício de determinada profissão. É uma entidade com natureza jurídica de autarquia especial, conforme entendimento do Tribunal de Contas da União, com a função de "zelar pela integridade e pela disciplina das diversas profissões, disciplinando e fiscalizando, não só sob o aspecto normativo, mas também punitivo, o exercício das profissões regulamentadas, zelando pela ética no exercício destas" (TRIBUNAL..., 2014). Isso leva a entender a importância da prática social atrelada a um tipo diferente de organização.

Foram utilizadas nesta pesquisa como fontes de evidências a análise documental e entrevistas com informantes-chave que compõem a organização. 0 CRA/SE conta com um corpo de quatro funcionários que compõem a estrutura administrativa (um funcionário para o atendimento, outro para o financeiro, uma fiscal e uma assessora da presidência). 0 Conselho também é composto por nove conselheiros titulares e nove suplentes, eleitos para uma gestão de quatro anos. As informações constam no site do conselho (CONSELHO..., 2015).

As categorias analíticas adotadas no trabalho são as práticas e os praticantes. Conforme Jarzabkowski,
Balogun e Seidl (2007), as pesquisas que interconectam práticas e praticantes podem analisar a prática de diferentes formas. Este trabalho adotará uma perspectiva baseada na teoria da prática reflexiva, para estudar simultaneamente as práticas e os praticantes. O Quadro 1 apresenta as categorias analíticas e seus elementos.

Quadro 1 - Categorias analíticas e elementos de análise

\begin{tabular}{|c|c|}
\hline Categorias & Elementos de análise \\
\hline Práticas & $\begin{array}{l}\text { - Planejamento estratégico; } \\
\text { - Reuniões e encontros; } \\
\text { - Regras e normas. }\end{array}$ \\
\hline Praticantes & $\begin{array}{l}\text { - Reflexão durante a prática; } \\
\text { - Análise de problemas; } \\
\text { - Ferramentas; } \\
\text { - Conhecimentos; } \\
\text { - Experiência. }\end{array}$ \\
\hline
\end{tabular}

Fonte: Elaborado pelos autores com base em Jarzabkowski, Balogun e Seidl (2007).

\section{ANÁLISE DOS RESULTADOS}

Os resultados foram coletados a partir de entrevistas realizadas na sede própria do CRA/SE com quatro funcionários do Conselho: o presidente (doravante identificado como "Alfa"), a secretária do presidente (identificada como "Beta"), o assistente financeiro (identificado como "Gama") e um dos conselheiros titulares (identificado como "Delta"). As mesmas perguntas foram feitas a cada um.

Em relação ao elemento de análise "Planejamento Estratégico", a participação de cada indivíduo na sua elaboração, de acordo com a opinião dos entrevistados, mostrou as seguintes características: a igualdade de participação e responsabilidade dos conselheiros; o uso de ferramentas ou sistemas de gestão; a atuação do Conselho Federal em termos de dotação orçamentária e do provimento de recursos; por fim, destaca-se 
a importância da pessoa do presidente do conselho, contradizendo o que foi afirmado em relação à igualdade entre os conselheiros.

Quadro 2 - Respostas a respeito do elemento de análise "Planejamento Estratégico"

\begin{tabular}{|l|l|}
\hline Entrevistados & \multicolumn{1}{|c|}{ Teor das Respostas } \\
\hline Alfa & $\begin{array}{l}\text { A responsabilidade e a participação } \\
\text { dos conselheiros na elaboração do } \\
\text { planejamento são iguais entre todos. } \\
\text { A elaboração do planejamento es- } \\
\text { tratégico contempla a implantação } \\
\text { do Balanced Scorecard (BSC) e do } \\
\text { Gerenciamento de Processos de Ne- } \\
\text { gócio (BPM). }\end{array}$ \\
\hline Beta & $\begin{array}{l}\text { A empresa a ser contratada para } \\
\text { elaborar o planejamento estratégi- } \\
\text { co levará em conta as opiniões dos } \\
\text { funcionários do Conselho, ealgumas } \\
\text { informações já foram coletadas de } \\
\text { forma preliminar pelos conselheiros. } \\
\text { Há um fundo de apoio específico do } \\
\text { Conselho Federal de Administração } \\
\text { para projetos específicos dos conse- } \\
\text { lhos regionais. }\end{array}$ \\
\hline Delta & $\begin{array}{l}\text { A definição do planejamento estra- } \\
\text { tégico fica condicionada à dotação } \\
\text { orçamentária estabelecida pelo } \\
\text { Conselho Federal, a partir das soli- } \\
\text { citações feitas Conselho Regional. O } \\
\text { orçamento necessário é baseado na } \\
\text { experiência anterior e em diálogos } \\
\text { com os conselheiros federais. }\end{array}$ \\
\hline Gama & $\begin{array}{l}\text { A implantação está condicionada à } \\
\text { mudança de diretoria, indicando que } \\
\text { o planejamento estratégico é vincu- } \\
\text { lado à pessoa do presidente do Con- } \\
\text { selho e às características pessoais de } \\
\text { liderança. }\end{array}$ \\
\hline
\end{tabular}

Fonte: Elaborado pelos autores com base nas entrevistas realizadas em campo
Segundo Mintzberg e outros autores (2007), a determinação da estratégia também considera, junto das considerações econômicas, as preferências do presidente e talvez dos associados imediatos, como valores pessoais, aspirações e ideais, as quais podem e devem influenciar a escolha final. Dessa forma, o que os executivos de uma empresa querem fazer deve ser considerado uma decisão estratégica.

Quanto ao elemento de análise "Reuniões e encontros", as respostas apresentam as opiniões dos entrevistados sobre a dificuldade dos conselheiros em conciliar as atividades fora do Conselho. Além da dinâmica de realização de reuniões ordinárias e extraordinárias. Para Jarzabkowski e Seidl (2005), uma postura reflexiva em relação aos ajustes estratégicos estabelecidos em reuniões só é alcançada caso haja uma distância crítica entre o profissional e os processos externos e orientações.

Quadro 3 - Respostas a respeito do elemento de análise "Reuniões encontros"

\begin{tabular}{|l|l|}
\hline Entrevistados & \multicolumn{1}{|c|}{ Teor das Respostas } \\
\hline Alfa & $\begin{array}{l}\text { A dinâmica das reuniões é afeta- } \\
\text { da pelo fato dos conselheiros te- } \\
\text { rem seus empregos fora do CRA, } \\
\text { sendo que em geral há as reuni- } \\
\text { ões mensais ordinárias, com re- } \\
\text { gistros de atas e também há reu- } \\
\text { niões esporádicas, para definir } \\
\text { algum detalhe envolvendo parte } \\
\text { dos conselheiros. }\end{array}$ \\
\hline Beta & $\begin{array}{l}\text { Além das reuniões ordinárias, re- } \\
\text { alizadas na segunda quinta-feira } \\
\text { de cada mês, há as reuniões extra- } \\
\text { ordinárias, convocadas de acordo } \\
\text { com a necessidade de algum con- } \\
\text { selheiro específico. }\end{array}$ \\
\hline
\end{tabular}




\begin{tabular}{|l|l|}
\hline Entrevistados & \multicolumn{1}{|c|}{ Teor das Respostas } \\
\hline Gama & $\begin{array}{l}\text { Muitas reuniões com os conse- } \\
\text { lheiros são bem informais, não } \\
\text { sendo registradas em ata, poden- } \\
\text { do inclusive ocorrer fora da sede } \\
\text { do CRA, devido à disponibilidade } \\
\text { dos conselheiros. }\end{array}$ \\
\hline Delta & $\begin{array}{l}\text { As reuniões ordinárias existem } \\
\text { para atendimento às normas, e } \\
\text { sua pauta normalmente não varia, } \\
\text { tratando de coisas do dia-a-dia das } \\
\text { atividades do conselho. Já as ex- } \\
\text { traordinárias seguem pautas mais } \\
\text { urgentes. }\end{array}$ \\
\hline
\end{tabular}

Fonte: Elaborado pelos autores com base nas entrevistas realizadas em campo.

Já em relação às regras e normas, as opiniões emitidas destacam a igualdade da participação dos conselheiros nas reuniões, em que o presidente possui a prerrogativa de abrir e encerrar os trabalhos. Silva e Silva (2011) afirmam que os gerentes também aprendem pessoalmente, por meio de uma reflexão coletiva, considerando fatores como aprendizagem, desenvolvimento e prática.

Quadro 4 - Respostas a respeito do elemento de análise "Regras e normas"

\begin{tabular}{|l|l|}
\hline Entrevistados & \multicolumn{1}{|c|}{ Teor das Respostas } \\
\hline Alfa & $\begin{array}{l}\text { Na reunião, todos falam. A minha } \\
\text { palavra não é mais importante que } \\
\text { a dos outros conselheiros. Cada um } \\
\text { busca falar o necessário, e todos } \\
\text { observam o tempo da reunião, para } \\
\text { não extrapolar. }\end{array}$ \\
\hline Beta & $\begin{array}{l}\text { Mensalmente, a pauta das reuni- } \\
\text { ões é elaborada pela assessora, que } \\
\text { pede sugestões dos funcionários e } \\
\text { conselheiros. }\end{array}$ \\
\hline
\end{tabular}

\begin{tabular}{|l|l|}
\hline Entrevistados & \multicolumn{1}{|c|}{ Teor das Respostas } \\
\hline Gama & $\begin{array}{l}\text { A participação dos funcionários nas } \\
\text { reuniões está diretamente relacionada } \\
\text { com a atividade exercida por cada um. }\end{array}$ \\
\hline Delta & $\begin{array}{l}\text { As reuniões são conduzidas pelo pre- } \\
\text { sidente, que se senta na cabeceira da } \\
\text { mesa e dita a palavra inicial e final } \\
\text { para tais reuniões, tomando-se o cui- } \\
\text { dado em relação ao tempo da reunião. }\end{array}$ \\
\hline
\end{tabular}

Fonte: Elaborado pelos autores com base nas entrevistas realizadas em campo.

As opiniões emitidas sobre a "reflexão durante a prática" mostram que os entrevistados têm dificuldade em conciliar a carga de trabalho com o tempo necessário para a reflexão, e a opinião corrente é a de que muitas atividades são feitas no "automático" ou, priorizando as atividades mais urgentes. A comunicação entre os membros do conselho reduz as dificuldades de conciliação, pois o confronto de opiniões leva a construção do conhecimento necessário à atividade profissional.

Em relação a esse fator, Schön (2000) aponta que há um contínuo diálogo introspectivo do profissional ao lidar com situações, problemas e imprevistos. Nesse diálogo interno se constroem e remodelam planos, experimentos, hipóteses e testes virtuais, realizados dentro da mente, em que problemas são definidos e redefinidos e os sentidos das situações práticas são elaborados de forma contínua, gerando um desempenho diferenciado na organização.

Quadro 5 - Respostas a respeito do elemento de análise "Reflexão durante a prática”

\begin{tabular}{|l|l|}
\hline Entrevistados & \multicolumn{1}{|c|}{ Teor das Respostas } \\
\hline \multirow{4}{*}{ Alfa } & $\begin{array}{l}\text { Os conselheiros conciliam a ativi- } \\
\text { dade do Conselho com outros em- } \\
\text { pregos e trabalhos, e muitas vezes } \\
\text { as ações são feitas no automático, } \\
\text { e não resta tempo para a reflexão, } \\
\text { muitas vezes. }\end{array}$ \\
\hline
\end{tabular}




\begin{tabular}{|l|l|}
\hline Entrevistados & \multicolumn{1}{|c|}{ Teor das Respostas } \\
\hline Beta & $\begin{array}{l}\text { Uma forma de mitigar a falta de tem- } \\
\text { po é a comunicação entre todos, di- } \\
\text { ferentes pontos de vista leva a uma } \\
\text { melhor compreensão da situação. }\end{array}$ \\
\hline Gama & $\begin{array}{l}\text { Refletir auxilia numa percepção } \\
\text { mais apurada da atividade exercida, } \\
\text { o que nem sempre é possível, devido } \\
\text { a questões como o tempo escasso, } \\
\text { grande carga de atividades, poucos } \\
\text { funcionários. Isso leva a uma ne- } \\
\text { cessidade de priorizar as atividades } \\
\text { mais urgentes ou importantes. }\end{array}$ \\
\hline Delta & $\begin{array}{l}\text { A reflexão necessariamente leva a } \\
\text { uma discussão da ideia com outras } \\
\text { pessoas, saber o que se pode me- } \\
\text { lhorar e aprimorar uma atividade. }\end{array}$ \\
\hline
\end{tabular}

Fonte: Elaborado pelos autores com base nas entrevistas realizadas em campo.

Em relação ao elemento "Análise de problemas", mais uma vez os entrevistados falaram da importância da comunicação, e que a questão do tempo escasso permeia a atividade do conselho. A resolução de problemas precisa ser imediata e os funcionários do Conselho se ocupam dos problemas do dia a dia, enquanto os conselheiros ficam com os problemas maiores, de cunho estratégico.

Souza-Silva e Davel (2007) estabelecem que o confronto da situação atual com situações familiares do passado ativa o processo reflexivo, de forma a ajudar o indivíduo a descobrir a melhor forma de realizar uma ação no contexto de uma nova prática. 0 evento familiar do passado atua como um precedente, uma metáfora que exemplifica o fenômeno não familiar. Tais experiências de reflexões enriquecem o repertório do profissional para que futuramente ele lide melhor com novas práticas.
Quadro 6 - Respostas a respeito do elemento de análise "Análise de problemas"

\begin{tabular}{|l|l|}
\hline Entrevistados & \multicolumn{1}{|c|}{ Teor das Respostas } \\
\hline Alfa & $\begin{array}{l}\text { A comunicação entre os conselhei- } \\
\text { ros é essencial. }\end{array}$ \\
\hline Beta & $\begin{array}{l}\text { A reflexão e a experiência profis- } \\
\text { sional caminham juntos, e só ao } \\
\text { participar ativamente da atividade } \\
\text { gerencial é possível extrair alguma } \\
\text { lição que torne possível a reflexão e } \\
\text { a melhoria contínua. }\end{array}$ \\
\hline Gama & $\begin{array}{l}\text { Considerando o tempo disponível } \\
\text { dos conselheiros e o tempo escasso, } \\
\text { a análise dos problemas precisa ser } \\
\text { rápida e focar na solução imediata, } \\
\text { pois acumular os problemas a se- } \\
\text { rem resolvidos é pior. }\end{array}$ \\
\hline Delta & $\begin{array}{l}\text { Há uma diferenciação dos proble- } \\
\text { mas pelo grau de dificuldade, os } \\
\text { problemas pequenos são resol- } \\
\text { vidos pelos funcionários direta- } \\
\text { mente, e grandes problemas são } \\
\text { tratados em plenária pelos conse- } \\
\text { lheiros, seguindo os trâmites do } \\
\text { serviço público. }\end{array}$ \\
\hline
\end{tabular}

Fonte: Elaborado pelos autores com base nas entrevistas realizadas em campo.

Quanto ao elemento de análise "Ferramentas", os entrevistados citaram as ferramentas de comunicação utilizadas ao longo do exercício das atividades, as quais são apontadas por Jarzabkowski (2004) como práticas de gestão que reúnem um componente técnico, analítico, orientado para o arranjo e coordenação dos recursos materiais. Essas práticas são também esquemas conceituais que auxiliam os estrategistas para gerar e impor significado em seus ambientes de forma a construir a atividade estratégica. 
Quadro 7 - Respostas a respeito do elemento de análise "Ferramentas"

\begin{tabular}{|l|l|}
\hline Entrevistados & \multicolumn{1}{c|}{ Teor das Respostas } \\
\hline Alfa & $\begin{array}{l}\text { As ferramentas de comunicação ser- } \\
\text { vem para a divulgação rápida de in- } \\
\text { formações e agir de forma rápida. }\end{array}$ \\
\hline Beta & $\begin{array}{l}\text { Telefone (redes sociais), para entrar } \\
\text { em comunicação com os conselhei- } \\
\text { ros, e-mail, de forma a conciliar a } \\
\text { agenda do presidente. }\end{array}$ \\
\hline Gama & Telefone, redes sociais, whatsapp. \\
\hline Delta & $\begin{array}{l}\text { O smartphone auxilia muito no pro- } \\
\text { cesso de comunicação. }\end{array}$ \\
\hline
\end{tabular}

Fonte: Elaborado pelos autores com base nas entrevistas realizadas em campo.

Em relação ao elemento de análise "Conhecimentos", além da legislação que regula as atividades do Conselho, além do conhecimento de normas e regulamentos gerais do setor público, é também necessário um conhecimento mais prático. 0 estilo gerencial tem influência na dinâmica do trabalho, visto que as experiências individuais são essenciais no processo de aprendizagem (SILVA; SILVA, 2011).

Quadro 8 - Respostas a respeito do elemento de análise “Conhecimentos”

\begin{tabular}{|l|l|}
\hline Entrevistados & \multicolumn{1}{|c|}{ Teor das Respostas } \\
\hline Alfa & $\begin{array}{l}\text { Regimento interno e as diretrizes } \\
\text { do Conselho Federal. O conheci- } \\
\text { mento das atividades no setor pú- } \\
\text { blico evita muitos problemas. }\end{array}$ \\
\hline Beta & $\begin{array}{l}\text { Um regimento interno conduz a } \\
\text { atividade do Conselho. A legisla- } \\
\text { ção do Conselho Federal de Ad- } \\
\text { ministraçãodelimita a atuação das } \\
\text { regionais, que possuem alguma } \\
\text { liberdade de estabelecer regras } \\
\text { sobre a atividade. }\end{array}$ \\
\hline
\end{tabular}

\begin{tabular}{|l|l|}
\hline Entrevistados & \multicolumn{1}{|c|}{ Teor das Respostas } \\
\hline Gama & $\begin{array}{l}\text { O conhecimento mais essencial } \\
\text { para o exercício de presidente do } \\
\text { conselho é o conhecimento em } \\
\text { administração pública, com ex- } \\
\text { periência anterior, pois isso faz } \\
\text { com que o gestor conheça a legis- } \\
\text { lação e possa tomar as decisões } \\
\text { que não venham a ferir as leis. O } \\
\text { funcionamento de um conselho } \\
\text { é diferente do funcionamento de } \\
\text { uma empresa privada. }\end{array}$ \\
\hline Delta & $\begin{array}{l}\text { A prática e o conhecimento acadê- } \\
\text { mico muitas vezes não combinam, } \\
\text { e as atividades são muito executa- } \\
\text { das no “automático”. }\end{array}$ \\
\hline
\end{tabular}

Fonte: Elaborado pelos autores com base nas entrevistas realizadas em campo.

Por fim, o elemento de análise "experiência" mostra que as opiniões dos entrevistados mostram que a renovação "forçada" da gestão é boa em termos de atualizar da entidade, mas ruim para executar atividades de longo prazo. Valorizam-se a atualização constante e o aprendizado a partir da experiência adquirida Silva e Silva (2011) apontam que o pensamento reflexivo busca alguma falha existente, uma solução não percebida e as nuances do momento da ação, integrando conhecimento e prática por meio da reflexão.

Quadro 9 - Respostas a respeito do elemento de análise "Experiência”

\begin{tabular}{|l|l|}
\hline Entrevistados & \multicolumn{1}{|c|}{ Teor das Respostas } \\
\hline \multirow{3}{*}{ Alfa } & $\begin{array}{l}\text { O Conselho faz parte da reali- } \\
\text { dade há mais de 15 anos, tendo } \\
\text { ingressado ainda como estagiá- } \\
\text { rio e com o pai tendo sido presi- } \\
\text { dente do Conselho, o que trouxe } \\
\text { familiaridade com os assuntos } \\
\text { do dia-a-dia. }\end{array}$ \\
\hline
\end{tabular}




\begin{tabular}{|l|l|}
\hline Entrevistados & \multicolumn{1}{|c|}{ Teor das Respostas } \\
\hline Beta & $\begin{array}{l}\text { O trabalho no conselho é uma } \\
\text { fonte de aprendizado constan- } \\
\text { te, a importância de se atualizar } \\
\text { constantemente. }\end{array}$ \\
\hline Gama & $\begin{array}{l}\text { Uma das particularidades do Con- } \\
\text { selho é que por um lado, os funcio- } \\
\text { nários efetivos trazem um aspecto } \\
\text { constante, enquanto os conselhei- } \\
\text { ros, que se renovam a cada quatro } \\
\text { anos, dão um aspecto de renova- } \\
\text { ção e mudança- essa tensão mar- } \\
\text { ca a atividade do conselho. }\end{array}$ \\
\hline Delta & $\begin{array}{l}\text { A renovação gera, em alguns as- } \\
\text { pectos, um problema para a exe- } \\
\text { cução de atividades a longo prazo. }\end{array}$ \\
\hline
\end{tabular}

Fonte: Elaborado pelos autores com base nas entrevistas realizadas em campo.

\section{CONCLUSÕES}

Os resultados mostram que a atuação individual é limitada pela estrutura organizacional e pelo pouco tempo para a reflexão. Isso indica que o Conselho não permite aos profissionais que potencializem a capacidade de se desenvolver e aprender fazendo, pois, segundo Reis, Silva e Eboli (2010), as organizações devem estimular uma postura ativa nas pessoas, para que elas busquem continuamente, por meio do questionamento e da reflexão, soluções criativas e inovadoras para os dilemas e imprevistos do cotidiano. Outra conclusão que se pode tirar é que a prática reflexiva é uma ferramenta valiosa na reconstrução da estratégia pela ação reflexiva dos atores, algo caro à perspectiva da Estratégia como Prática Social.

É preciso estabelecer que não é pretensão do presente artigo gerar generalizações estatísticas, visto que, como estabelecem Mariotto, Zanni e Mo- raes (2014), ao se tratar de um estudo de caso único, ele tem distintas possibilidades de generalização, a partir de nuances do fazer estratégico que geram insights para novas pesquisas. Assim, pode-se dizer que o campo da prática reflexiva, dentro da teoria organizacional, ainda é incipiente e carece de pesquisas fundamentadas em outras escolas de pensamento, que considerem a importância do aprendizado com base na própria experiência como benefício para as empresas que ofereçam as condições necessárias para a construção desse conhecimento de forma contínua.

\section{REFERÊNCIAS}

CLARÀ, M. What is reflection? Looking for clarity in an ambiguous notion. Journal of Teacher Education, 2014. p.1-11,

CONSELHO Regional de Administração de Sergipe CRA-SE. Disponível em: <http://www.crase.org.br/>. Acesso em: 17 jan. 2015.

JARZABKOWSKI, P. Strategy as Practice: recursiveness, adaptation, and practices-in-use.

Organization Studies, v.25, n.4, 2004. p.529-560.

JARZABKOWSKI, P.; BALOGUN, J.; SEIDL, D.

Strategizing: the challenges of a practice perspective.

Human Relations, v.60, n.1, 2007. p.5-27.

JARZABKOWSKI, P.; SEIDL, D. Meetings as strategizing episodes in the becoming of organizational strategy. In: Organizations Studies Summer Workshop, I, 2005, Míconos. Anais Míconos: SAGE, 2005.

JARZABKOWSKI, P.; SPEE, A.P. Strategy-as-practice: $A$ review and future directions for the field.

International Journal of Management Reviews, v.11, n.1, p.69-95, 2009. 
JOHNSON, G. et al. Strategy as practice: research directions and resources. Cambridge: Cambridge University Press, 2007.

MARIOTTO, F.L.; ZANNI, P.P.; MORAES, G.H.S.M. What is the use of a single-case study in management research? Revista de Administração de Empresas, v.54, n.4, 2014. p.358-369.

MINTZBERG, H. et al. 0 processo da estratégia: conceitos, contextos e casos selecionados. 4.ed. Porto Alegre: Bookman, 2007.

REIS, G. G.; SILVA, L.M.T.; EBOLI, M.P. A prática reflexiva e suas contribuições para a educação corporativa. REGE - Revista de Gestão, v.17, n.4, 2010. p.403-419.

ROGLIO, K. D. Sharing experiences as a source of learning: comparing an American with a Brazilian executive MBA program. Revista de Administração FACES Journal, v.8, n.3, 2009. p.29-40.
SAUNDERS, M.; LEWIS, P.; THORNHILL, A. Research Methods for Business Students. 4.ed. Harlow: Pearson Education, 2007.

SCHÖN, D.A. Educando o profissional reflexivo. Porto Alegre: Artmed, 2000.

SILVA, L.B.; SILVA, A.B. A reflexão como mediadora da aprendizagem gerencial em Organizações Não Governamentais. Revista de Administração Mackenzie, v.12, n.2, 2011. p.55-89.

SOUZA-SILVA, J.C.; DAVEL, E. Da ação à colaboração reflexiva em comunidades de prática. Revista de Administração de Empresas, v.47, n.3, 2007. p.53-65.

TRIBUNAL de Contas da União. Orientações para os conselhos de fiscalização das atividades profissionais. Brasília: Tribunal de Contas da União, 2014.

WHITTINGTON, R. Strategy as practice. Long Range Planning, v.29, n.5, 1996. p.731-735. 
Recebido em: 11 de janeiro de 2016 Avaliado em: 3 de junho de 2016 Aceito em: 21 de junho de 2016
1. Mestre em Administração pela Universidade Federal de Sergipe - UFS; Analista Superior II da Empresa Brasileira de Infraestrutura Aeroportuária (Infraero).E-mail: thiagorzv@yahoo.com.br

2. Doutora e Mestre em Administração pela Universidade Federal do Paraná UFPR; Professora adjunta da Universidade Federal de Sergipe - UFS. E-mail: ludmilla2907@gmail.com 